bias (younger patients with severe pain potentially more likely to respond than those with milder pain). The majority of support was provided informally, and this could be for a number of reasons. For example, lack of awareness/not meeting eligibility/unable to afford formal social care, or preference to be cared for by familiar persons. This should be explored in future research. These results demonstrate the burden of social care may be significantly greater than government and social care organisations are aware, with important implications for policy and planning.

Disclosure of Interests: Jenny Humphreys: None declared, Katy Dempsey: None declared, Ollie Phelan: None declared, Laura Boothman: None declared, Louise Cook: None declared, William Dixon Consultant of: Bayer and Google DOI: 10.1136/annrheumdis-2020-eular.2321

\section{THU0552 SWITCH TO BIOSIMILAR ADALIMUMAB - IS IT COST EFFECTIVE?}

J. Begum ${ }^{1}$, M. K. Nisar ${ }^{1} .{ }^{1}$ Luton and Dunstable University Hospital, Luton, United Kingdom

Background: Since the introduction of anti-TNF biosimilars in routine clinical practice, there has been a drive to implement the switch program for all biosimilars at the point of availability. First adalimumab biosimilar was granted marketing authorisation by the EMA in March 2017. Our Trust was aligned to NHS England strategy which required adoption of biosimilar within three months for new patients and one year for switchers. This could help deliver significant savings to the NHS whilst achieving similar clinical outcomes.

Objectives: We report our early experience of introducing adalimumab biosimilar (SB5).

Methods: A list of all patients prescribed adlimumab was extracted through our database. A 'switch' letter was drafted and sent to all patients including Imraldi information sheet. Patients were given the opportunity to contact nurse helpline for information or if disease control worsened/adverse effects developed. We reviewed all relevant records and collected data on any adverse events and disease outcome on either side of the switch. Patients were reviewed as originally planned by their respective clinicians.

Results: 198 patients were identified established on adalimumab. All had switched by October 2019 to Imraldi. Mean age of switchers was 48 (range $16-83$ years). Gender distribution was equal (99 each). 35 (17\%) were Asian, two Afro-Caribbean, four other and the remaining 157 (80\%) were White Caucasian. 54 (27\%) had RA, 81 (41\%) PsA, 57 (29\%) AS and six had JIA. Coprescribed DMARDs included methotrexate $(n=53,27 \%)$, sulfasalazine $(n=15,7.5 \%)$, hydroxychloroquine $(n=14,7 \%)$ and leflunomide in two individuals. $83(42 \%)$ participants were prescribed adalimumab monotherapy.

Prior to switch, median DAS28 for RA group was 2.28 (0.57-6.29). Median BASDAI and spinal VAS for AS cohort was $3.3(0.8-8.8)$ and $3.0(0-9)$ respectively. Tender and swollen joint components for PSARC were median three (0-8 tender, $0-6$ swollen) in PsA group. Only $30 \%$ of the patients had been reviewed face-to-face following the switch. Their respective median disease activity indices were not significantly different from pre-switch assessments. Fifteen (7.5\%) patients switched back to the originator for following reasons; injection site reaction $(n=7)$, loss of disease control $(n=7)$ and inability to use the new device $(n=1)$.

Conclusion: Our experience of switching adalimumab patients has been reasonably successful. All were happy to switch after receiving a letter and having the opportunity to contact if necessary. Substantial annual cost savings of over $£ 300,000$ have been projected for this financial year. At group level there were no major differences in disease outcomes and $90 \%$ reported no issues. However, just under $10 \%$ of those reviewed have decided to return to the originator within three months of switch with loss of efficacy and thereby confidence in the drug. We support the routine switching from originator to biosimilar adalimumab however close monitoring is required certainly in the first few weeks of dose administration.

Disclosure of Interests: Julie Begum: None declared, Muhammad Khurram Nisar Grant/research support from: Muhammad Nisar undertakes clinical trials and received support (including attendance at conferences, speaker fees and honoraria) from Roche, Chugai, MSD, Abbvie, Pfizer, BMS, Celgene, Novartis and UCB, Consultant of: Muhammad Nisar undertakes clinical trials and received support (including attendance at conferences, speaker fees and honoraria) from Roche, Chugai, MSD, Abbvie, Pfizer, BMS, Celgene, Novartis and UCB, Speakers bureau: Muhammad Nisar undertakes clinical trials and received support (including attendance at conferences, speaker fees and honoraria) from Roche, Chugai, MSD, Abbvie, Pfizer, BMS, Celgene, Novartis and UCB

DOI: 10.1136/annrheumdis-2020-eular.1975

\section{THU0553 \\ A HEALTH ECONOMIC ANALYSIS OF THE USE OF COLOUR DOPPLER ULTRASONOGRAPHY AS THE PRIMARY DIAGNOSTIC MODALITY IN PATIENTS WITH SUSPECTED GIANT CELL ARTERITIS}

C. Mukhtyar ${ }^{1,2}$, L. Steel ${ }^{1}$, C. Jones ${ }^{1}$, M. Bachmann ${ }^{2} .{ }^{1}$ Norfolk \& Norwich University Hospital, Norwich, United Kingdom; ${ }^{2}$ University of East Anglia, Norwich, United Kingdom

Background: EULAR has recommended ultrasonography (US) as first imaging modality for diagnosis of Giant Cell Arteritis (GCA) ${ }^{1}$. For patients with a high pre-test probability who have a negative scan, the recommendation is to use another diagnostic modality like temporal artery biopsy (TAB) to make a diagnosis $^{1}$. We know that a fast-track pathway incorporating US, results in better clinical outcomes $^{2}$; but there are little data on the health-economics of this approach. Since 2017, we have used ultrasonography as the primary diagnostic modality for suspected GCA. In patients with a high pre-test probability with a negative ultrasonography, we perform a temporal artery biopsy.

Objectives: To compare the cost of investigating GCA using first-line US and second-line TAB the use of TAB only. To compare the cost per definite diagnosis of GCA.

Methods: Number of cases from 2007-2009 and 2017-2019 were calculated by the number of TAB performed and number of referrals to hospital GCA clinic respectively. Costs of the procedure were calculated as per the nationally agreed tariff by the United Kingdom National Health Service. For ease of comparison, we used the 2018/19 tariff ( $£ 1284 / T A B$; $£ 51$ for US)

Results: In 2007-2009, 162 cases were referred to clinic and had a TAB, of which 86 were positive. No cases had US. The $2018 / 19$ corrected cost was £208008; the cost per positive diagnosis was $£ 2418.70$ (Table 1).

Table 1. Numbers of cases investigated for suspected GCA by TAB or US and the costs corrected to 2018/19 UK NHS tariff.

\begin{tabular}{|c|c|c|c|c|c|c|}
\hline Years & $\begin{array}{l}\text { No of } \\
\text { referrals }\end{array}$ & No of TAB & No of US & $\begin{array}{c}\text { No of } \\
\text { patients with } \\
\text { GCA }\end{array}$ & Total cost & $\begin{array}{l}\text { Cost of mak- } \\
\text { ing } 1 \text { positive } \\
\text { diagnosis }\end{array}$ \\
\hline 2007-09 & 162 & 162 & 0 & 86 & $£ 208008$ & $£ 2418.70$ \\
\hline 2017-19 & 419 & 69 & 416 & 142 & $£ 109812$ & $£ 773.32$ \\
\hline
\end{tabular}

In 2017-2019, 419 patients were referred to the GCA clinic, 416 of whom had US for diagnosis. 3 individuals had a TAB as the first diagnostic modality and 66 others were referred for $\mathrm{A}$ TAB because of a high pre-test probability and negative US. The $2018 / 19$ corrected cost of this pathway was $£ 109812$ and the cost pe positive diagnosis was $£ 773.32$ (Table 1).

If all cases in 2017-2019 had a TAB for suspected GCA, the 2018/19 corrected cost would have been $£ 537996$. The estimated $2018 / 19$ corrected savings in our center was $£ 142728 /$ year. The estimated $2018 / 19$ corrected savings per definite diagnosis of GCA has dropped by $£ 1645.37$ (Table 1).

Conclusion: The EULAR recommendation of using first-line US for diagnosis of GCA followed by a TAB in cases with uncertain diagnosis after US, is highly cost-effective in the UK, resulting in cost savings of $>£ 140 \mathrm{~K}$ per year.

References:

[1] Dejaco C, et al. Ann Rheum Dis. 2018 May;77(5):636-643.

[2] Diamantopoulos AP, et al. Rheumatology (Oxford). 2016 Jan;55(1):66-70.

Disclosure of Interests: None declared

DOI: 10.1136/annrheumdis-2020-eular.749

\section{THU0554 COMORBIDITY AND HEALTH CARE UTILIZATION IN PERSONS WITH SJÖGREN'S SYNDROME: A CLAIMS DATA ANALYSIS}

K. Albrecht ${ }^{1}$, T. Dörner ${ }^{2}$, I. Redeker ${ }^{1}$, K. Karberg ${ }^{3}$, U. Marschall ${ }^{4}$, A. Zink ${ }^{1,2}$, J. Callhoff ${ }^{1} .{ }^{1}$ German Rheumatism Research Centre, Epidemiology, Berlin, Germany; ${ }^{2}$ Charité University Medicine, Berlin, Germany; ${ }^{3}$ Rheumapraxis Steglitz, Berlin, Germany; ${ }^{4}$ BARMER Statutory Health Insurance Fund, Berlin, Germany

Background: Sjögren's syndrome (SS) can affect numerous organs, including the muscles, the peripheral nervous system, kidneys and lungs. Epidemiological studies assessing comorbidity and health care utilization are needed to improve health care for this multifaceted disease.

Objectives: To capture comorbidity and medication of persons with SS in a pop ulation-based cohort in comparison to matched controls.

Methods: Individuals with an outpatient diagnosis of M35.0 (ICD-10) in $\geq 2$ quarters of a year or an inpatient diagnosis of M35.0 were identified in a German 